habituation training session was not a reliable index of subsequent startle tendency. This is important, because it could be argued that the lower startle level of Group 16-1000 in comparison to Group 2-1000 could have been due to some fatigue-like effect, since Group 16-1000 gave so many more responses than Group 2-1000 during training $(\bar{X}=451$ vs 184$)$. Comparison of Groups $16-1000$ and 2.8000 revealed, however, that Group 2-8000 gave many more responses over its entire training session than Group $16.1000(\bar{X}=976$ vs $451, \mathrm{t}=4.07, \mathrm{df}=46, \mathrm{p}<.001$ ) yet still was less habituated at the $120-\mathrm{dB}$ test intensity. While it is possible that a more critical factor might be the number of responses made just prior to testing (e.g., during the last 100 tones during training), which was obviously greater for Group 16-1000 than for Group 2-8000 (Fig. 1), this same comparison could not account for the difference between Groups $2-8000$ and 2.1000, since Group 2-8000 had fewer startles immediately prior to testing, yet was more habituated. It would appear, therefore, that there was no simple relationship between either the total number of responses made during training or the number of responses given immediately prior to testing and degree of habituation, thus making a fatigue interpretation difficult.

In an effort to explain the greater habituation following training on long rather than short ISIs, it has been suggested that this may be a result of differences in the degree to which stimuli are allowed to "consolidate" during training (Davis, in press). Another possibility might be to assume that the different degrees of habituation reflected a difference in the perceived intensity of the tones during training. Thus, it might be the case that the shorter the interval between two tone exposures the lower will be the perceived intensity or loudness of the second. This would suggest, therefore, that the average loudness of the tones during training was less for the 2-sec than for the 16-sec Ss. Since it has been shown (Davis \& Wagner, 1968) that the less intense a tone has been during training the less habituation it will produce as measured during a subsequent test session, prediction based on an intensity interpretation of the ISI effect would be consistent with previous data. Moreover, this line of reasoning would suggest that the ISI effect is simply a special case of a more fundamental intensity effect.

\section{REFERENCES}

DAVIS, M. Effects of interstimulus interval length and variability on startle response habituation in the rat. Journal of Comparative \& Physiological Psychology, in press.

DAVIS, M., \& WAGNER, A. R. Startle responsiveness after habituation to different intensities of tone. Psychonomic Science, $1968,12,337-338$.

KORN, J. H., \& MOYER, K. E. Habituation of the startle response and of heart rate in the rat. Canadian Journal of Psychology, 1966, 20, 183-190.

\title{
The relationship of nonprotein nitrogen and total nitrogen in rat brain to avoidance-extinction behavior
}

\author{
MARTIN GOLD, MORTON H. KLEBAN, HENRY ALTSCHULER, \\ M. POWELL LAWTON, and MARK MILLER
}

Gerontological Research Institute, Philadelphia Geriatric Center, Philadelphia, Pa. 19141

Equal, independent groups of young and aged albino rats were divided among avoidance-plus-extinction, avoidance, and nontraining conditions. Estimates of brain nonprotein nitrogen (NPN) were calculated from protein and total nitrogen values. Significant differences in NPN were found for the three brain sections. The aged animals had higher concentrations of NPN than the young in the avoidance-plus-extinction training condition. These values were significantly correlated with extinction behavior in the aged but not in the young Ss.

Our laboratory has been engaged in studies of the neurochemical changes occurring during avoidance behavior. In a previous paper, estimates of nonprotein nitrogen (NPN) were made from protein and total nitrogen quantities analyzed from the supernatant prepared from total brain tissue. In this report NPN values were calculated for cerebral, brain stem, and cerebellar sections. Both young (Kleban, Gold, Altschuler, Lawton, \& Miller ${ }^{1}$ ) and aged (Altschuler, Lawton, Kleban, Gold, \&
Miller, 1970) rats were investigated to determine if aging caused any difference in response. Chemical analyses were performed on total material in each of the three brain sections.

\section{METHOD}

The experimental apparatus was a 30-in.-long automated straight runway maze. By the rotation of end boxes, acting alternately as start- and goalboxes, around a stationary stem, animals could receive aversive training without handling between trials. It was a massed training procedure, the time between any two trials being 16 sec. The Es will supply a detailed description of the apparatus and the methodology upon request.

The Ss were 72 albino Wistar rats. There were 36 young (60-75 days old) and 36 aged $(\geqslant 24$ months old) rats. By random assignment, the young and aged rats were placed into three experimental conditions: (1) avoidance training; (2) avoidance plus extinction training; and (3) no training (controls). The avoidance group received limited avoidance training for 20 consecutive trials. In limited avoidance training, electric shock (1.0-mA intensity) was experienced on each trial, but the animal could avoid it by action on a section of the grid. After the 20 shock trials, the animals were placed into the experimental cages for $2 \mathrm{~h}$ before being sacrificed by decapitation. In the avoidance-plus-extinction group, after the 20 limited avoidance trials, the rats were given a maximum of 40 extinction trials. Extinction was defined as remaining on the grid for $60 \mathrm{sec}$. Thus, rats could have extinction scores ranging from 1 to 40 trials. These rats were also returned to their experimental cages for $2 \mathrm{~h}$ before decapitation. Control Ss were placed in experimental cages and housed for $2 \mathrm{~h}$ in the experimental room before being decapitated.

The experiment was conducted first on the young rats (Kleban et al, 1970). Chemical analyses were conducted on the brains of single animals. The brains were divided into cerebral, brain stem, and cerebellar sections. The chemical constituents analyzed were RNA, protein, and total nitrogen from the total brain tissue of each section. The experiment was then replicated on aged rats (Altschuler et al, 1970).

The animals were killed by decapitation with a Harvard guillotine and the three brain sections were isolated and homogenized individually for chemical analysis. Protein was analyzed using the procedure of Lowry (1951) and the total nitrogen was assayed by the micro-Kjeldahl method (Koch \& McMeekin, 1924). Commercial RNA and Versatol were used 
Table 1

Correlations Between Nonprotein Nitrogen (NPN) and Total Nitrogen With Avoidance Extinction Behavior

\begin{tabular}{lccc}
\multicolumn{1}{c}{ Subject } & Cerebrum & \multicolumn{1}{c}{$\begin{array}{c}\text { Brain } \\
\text { Stem }\end{array}$} & Cerebellum \\
\hline Young (NPN) & .34 & -.06 & -.15 \\
$\begin{array}{l}\text { Aged (NPN) } \\
\text { Young (Total } \\
\text { nitrogen vs NPN) }\end{array}$ & $-.59^{*}$ & $-.55^{*}$ & -.33 \\
$\begin{array}{l}\text { Aged (Total nitro- } \\
\text { gen vs NPN) }\end{array}$ & $.92^{* *}$ & .23 & $.68^{* *}$ \\
\hline
\end{tabular}

${ }^{*} p \leqslant .05,{ }^{*} p \leqslant .01$

as standards. All analyses were performed in duplicate.

NPN was estimated as follows: NPN $=$ total nitrogen concentration - $16 \%$ (protein concentration).

\section{RESULTS}

Statistical Analysis

of Neurochemical Constituents

The data were analyzed by a Lindquist Type 111 mixed analysis of variance design (1953). Significant $F$ ratios were found between young and aged $S s \quad(F=4.11$, $\mathrm{df}=1 / 66, \mathrm{p}<.05)$ and among the anatomical sections $(F=49.61, \mathrm{df}=2 / 132$, $\mathrm{p}<.001$ )

The combined means for aged and young Ss were $4.18 \mathrm{mg} / \mathrm{g}$ of wet weight tissue and $3.14 \mathrm{mg} / \mathrm{g}$ of wet weight tissue, respectively. The NPN value for the aged Ss was higher. Fisher $t$ tests were used to determine which anatomical sections or training conditions between the young and aged Ss were contributing to the differences found in the $F$ test. A mean difference of 1.72 was required for t-test significance at the .05 probability level. The mean differences between the aged and young were as follows: cerebrum (0.56), brain stem (1.51), cerebellum (1.04), avoidance plus extinction training $(1.74, p<.05)$, avoidance $(0.45)$, and controls $(0.94)$. Only the avoidance-plus-extinction comparison between the young and aged $\mathrm{Ss}$ was significant.

The $\mathbf{F}$ of 49.61 for anatomical sections indicated very strong differences among the NPN values expressed as $\mathrm{mg} / \mathrm{g}$ of wet weight of tissue for the cerebrum $(\mathrm{M}=5.18)$, brain stem $(\mathrm{M}=3.60)$, and cerebellum $(\mathrm{M}=2.21)$. These included both young and aged Ss, with the mean

Table 2

Correlations Between Anatomical Sections for Young and Aged Subjects for the Avoidance Plus Extinction Training Condition

\begin{tabular}{lccc}
\hline Subjects & $\begin{array}{c}\text { Cerebrum } \\
\text { vs Brain } \\
\text { Stem }\end{array}$ & $\begin{array}{c}\text { Cerebrum } \\
\text { vs Cere- } \\
\text { bellum }\end{array}$ & $\begin{array}{c}\text { Brain } \\
\text { Cerebellum }\end{array}$ \\
\hline Young & $.65^{*}$ & $.66^{* *}$ & $.80^{* *}$ \\
Old & $.55^{*}$ & $.64^{* *}$ & $.55^{* *}$ \\
\hline
\end{tabular}

${ }^{*} p=.05,{ }^{* *} p=.01$ differences between the cerebrum and brain stem $\left(M_{D}=1.58, \quad p<.001\right)$ cerebrum and cerebellum $\left(\mathrm{M}_{\mathrm{D}}=2.97\right.$ $\mathrm{p}<.001$ ), and brain stem and cerebellum $\left(\mathrm{M}_{\mathrm{D}}=1.37, \mathrm{p}<.001\right)$ all being strongly significant. The NPN values were highest in the cerebrum, next highest in the brain stem, and lowest in the cerebellum. Correlational Analyses

There were no differences between the avoidance extinction scores for the young $(M=29.33, \quad S D=6.20)$ and aged $(M=29.66, S D=5.64 ; t=.13, d f=22) S s$. The NPN values were correlated with these extinction scores (refer to Table 1). None of the correlations for the young Ss were significant. However, significant negative correlations were found for the cerebrum $(\mathrm{r}=.59, \mathrm{p}<.05)$ and the brain stem $(\mathrm{r}=.55, \mathrm{p}<.05)$ in the aged Ss. The negative correlation implies that Ss who extinguish quickly have higher NPN values. For the aged animals (Table 1) nitrogen and NPN have very high levels of covariability: cerebrum, $r=.92, p<.01$; brain stem, $r=.89, p<.01 ;$ and cerebellum, $r=.91, p<.01$. In the young animals, however, NPN and total nitrogen are uncorrelated for the cerebrum $(r=.11)$ and brain stem $(r=.23)$ and significantly correlated in the cerebellum $(\mathrm{r}=.68$, $\mathrm{p}<.01)$.

Correlations between anatomical sections for the young and aged animals are listed in Table 2. Since the differences in NPN concentration among anatomical sections are considerable, the question arises as to whether or not the quantities of NPN are correlated with each other. As seen, significant correlations exist for both aged and young Ss.

\section{DISCUSSION}

Most of the important compounds of biological interest contain nitrogen. Thus, the measurement of the total nitrogen present in the various brain sections provides a rough index of the quantity of material contained therein. Since the protein content contributed a significant amount of nitrogen and it was possible to derive a good estimate of this value, the nonprotein nitrogen was calculated. The NPN concentration then permitted correlational analyses to be carried out to see if any significant relationships existed between the amount of NPN and the behavior of the rats during limited avoidance training.

There were differences in concentration of the neurochemical entities measured in each anatomical section. It might be supposed that areas high in RNA would also show greater protein levels. However, the control condition comparison demonstrated that the protein concentration was lowest in the cerebrum where RNA (Kleban et al, 1970) ${ }^{1}$ and NPN were the highest.

The correlation of behavior with NPN showed a significant negative value for the cerebrum and brain stem in the aged animals. The young animals also had the same concentration relationship as the aged, i.e., NPN and RNA being highest in the cerebrum, yet only in the older rats was this amount correlated with behavior. The NPN pool in the aged animals might contain a greater concentration of some component directly relevant to the training task. In this regard attention should be called to the significant covariability of NPN with total nitrogen, which was significant in the aged rats but not in the young ones. NPN and total nitrogen are each a separate measure. The total nitrogen value includes protein (about $80 \%$ of the concentration), nucleic acid (in the neighborhood of $1 \%-2 \%$ ), and other small molecules such as nucleotides and amino acids. The NPN calculation removes protein from consideration. It might be conjectured that since protein nitrogen comprised the bulk of the total nitrogen that any correlations found would be due to this component. That is, the relationship would be a spurious one. Indeed, the relationship bewteen NPN and total nitrogen with behavior was a strong one, but this was only reflected in the aged cerebrum and brain stem and not in the young. The fact that this correlation held for NPN in the aged cerebrum and brain stem but not in the young group lends support for the hypothesis that the NPN phenomena were due to constituents present within this pool rather than to an adventitious relationship with protein.

\section{REFERENCES}

ALTSCHULER, H., KLEBAN, M. H., GOLD, M., \& LAWTON, M. P. Chemical changes in the brain and their relationship to donor-recipient transferred avoidance behavior in rats. Journal of Biological Psychology, 1968, 10, 4-9.

ALTSCHLLER, H., LAWTON, M. P., KLEBAN, M. H., GOLD, M., \& MILLER, M. Neurochemical changes in the brain of aged albino rats resulting from avoidance learning. Journal of Gerontology, in press.

LOWRY, O. H., ROSEBROUGH, N. J., FARR, A. L., \& RANDALL, R, J, Protein measurement with the folin phenol reagent. Journal of Biological Chemistry, 1951, 193, 265-275.

KOCH, F. C., \& McMEEKIN, T. L. A new direct Nesslerization micro-Kjeldahl method and a modification of the Nessler-Folin reagent for ammonia. Journal of the American Chemical Society, 1924, 46, 2066-2069.

LINDQUIST, E. D. Design and analysis of the experiments in psychology and education. New York: Houghton Mifflin, 1953. NOTE

1. Kleban, M. H., Gold, M., Altschuler, H., Lawton, M. P., \& Miller, M. Neurochemical changes in the brain of albino rats resulting from avoidance learning, unpublished data, 1970.

2. Supported by NIH Grant FR-05611. 